\title{
Development of high fiber rich antioxidant biscuits from purple and orange sweet potato peels
}

\author{
"Bakar, M.F.A., Ranneh, Y. and Kamil, N.F.M. \\ Department of Technology and Natural Resources, Faculty of Applied Sciences and Technology University \\ Tun Hussein Onn Malaysia, Pagoh Campus, Jorak, 84500 Bukit Pasir, Johor, Malaysia
}

\begin{abstract}
Article history:
Received: 14 February 2021

Received in revised form: 18 March 2021

Accepted: 22 May 2021

Available Online: 9 January 2022
\end{abstract}

\section{Keywords:}

Sweet potato peel,

Functional food,

Biscuit,

Antioxidant,

Dietary fibre

DOI:

https://doi.org/10.26656/fr.2017.6(1).036

\begin{abstract}
Sweet potato peel (SPP), which consist of various natural bioactive compounds, could play an important role in ameliorating chronic diseases such as cancer, cardiovascular diseases, and other degenerative diseases and yet remained underutilized. The current study investigated the effect of orange or purple SPP powder at different level of substitution $(2,5,10 \%)$ in the production of biscuits on the proximate, antioxidant potentials and consumer acceptance. Dietary fibre increased significantly $(\mathrm{P}<0.05)$ with an increase in SPP powder, ranging from 2 to $2.3 \mathrm{~g} / 100 \mathrm{~g}$. The total phenolic content of the biscuits was between 101.21 and $147.7 \mathrm{GAE} / \mathrm{mL}$, total flavonoid ranged from 22.7 to 42.2 RU/mL, ABTS radical content ranged from 2.7 to 42.2 ( $\mu \mathrm{g}$ ascorbic $/ \mathrm{mL}$ ). Acceptable biscuits were obtained by incorporating $2 \%$ SPP powder. Thus, SPP powder could be used as a functional and nutraceutical ingredient in biscuit production.
\end{abstract}

\section{Introduction}

Tuber and root crops are significant sources of several natural compounds, such as saponins, phenolic compounds, glycoalkaloids, phytic acids, carotenoids, and ascorbic acid (Chandrasekara and Kumar, 2016). Several scientific investigations have mentioned that root crop extracts, especially yam and sweet potato have radical scavenging activities. These activities are due to its phytochemical content, including ascorbic acid, alpha -tocopherol, beta-carotene and polyphenols (Bhandari and Kawabata, 2004; Kalt, 2005; Rumbaoa et al., 2009). These phytochemical compounds have attained a great interest in nutrition because of their ability in promoting human's health and preventing chronic diseases as antioxidants (Lampe, 1999). The nutritional management of different diseases has been usually attached with a diet rich in antioxidants and dietary fibres (Lattimer and Haub, 2010).

Peel from fruits, vegetables and tubers has healthy value content. Pear cultivar showed that the peel contains 25 times more amount of total phenolic content and high antioxidant rather than in flesh (Cruz-Bravo et al., 2019). Citrus sinenesis, which is a tropical fruit, is proceed into juice with $20 \%$ peels waste. This fruit wastes are prone to microbial growth and thus causing environmental pollution (Rafiq et al., 2018). Earlier scientific reports have concluded that some of these peels are rich in dietary fibre with good antioxidant properties (SernaCock et al., 2016).

Dietary fibre has been identified as the indigestible part of plant which assist in the movement of bowel and waste efficiently (Mcrorie and Fahey, 2013). Fruits, vegetables and cereals are the major source of dietary fibre (Bakar et al., 2015). However, low-fibre intake has been prominent in the current lifestyle, and therefore dietary fibres have been presented as a nutraceutical supplement. However, those supplements could not be used in conventional food, meal or diet. Therefore, incorporating dietary fibres into commercial food are encouraged to meet the recommended daily intake.

Purple and orange sweet potato have been known as a healthy food additive and a potential source of natural food colorants because of their high levels of anthocyanins. Ayamurasaki purple sweet potato contains $59 \mathrm{mg}$ of anthocyanin for each $100 \mathrm{~g}$. Anthocyanin derivatives such as peonidins and cyaidins have been reported to be responsible for the antioxidant activities in the peel of purple sweet potato (Han et al., 2007). The concentration of these promising-healthy flavonoids is mainly found in the peels more than the inner cortex (Liu et al., 2018).

Biscuits are one of the most common consumed food in the world. The affordable cost, good nutritional 
quality, availability in different tastes and long shelf-life are the main reasons for wide consuming (Boobier et al., 2006). Currently, different types of cereals such as oat bran, wheat bran, rice bran are utilized in bakery production to increase the fibre content (Lebesi and Tzia, 2011). However, the nutritional quality of dietary fibres in vegetables and fruits have higher proportion of soluble dietary fibre and bioactive compounds than the cereals (Arslan et al., 2019). Therefore, developing baking foods rich in fibre content by utilizing waste by-product is a healthy-promising approach and could decrease the negative environment effect. The aim of the present research is to develop biscuits rich in fibre and antioxidants from sweet potato peel, and to evaluate their physiochemical, biochemical and sensory characteristics.

\section{Materials and methods}

\subsection{Materials}

Wheat flour used in the study was purchased from the Universiti Tun Hussein Onn Malaysia market, Batu Pahat, Malaysia. Orange and purple sweet potato were harvested at maturity age from a commercial farmland located in Cameron Highlands, Pahang, Malaysia. The other reagents used in this study were of analytical grade.

\subsection{Sample preparation}

\subsubsection{Preparation of sweet potato peel powder}

The orange and purple sweet potato peel powder were prepared according to Ben Jeddou et al. (2017) with slight modification. The purple and orange sweet potato was washed with distilled water and peeled with a hand knife. After drying the peels with a hot air oven at $60^{\circ} \mathrm{C}$ for $24 \mathrm{hrs}$, the peels were grounded into powder which was cooled and sieved $(150 \mu \mathrm{m}$ mesh size $)$ to obtain the orange and sweet potato peel flour. Then, the sweet potato peel flour was stored at $4^{\circ} \mathrm{C}$ inside airtight polyethylene packs prior to use.

\subsubsection{Biscuits preparation}

Normal biscuits were prepared as a control and compared with orange sweet potato peel (OSPP) and purple sweet potato peel (PSPP) biscuits. The normal biscuits were processed from dough containing $140 \mathrm{~g}$ flour, $45 \mathrm{~g}$ sugar, $125 \mathrm{~g}$ butter and 1 teaspoon of baking soda as described by Ajila et al. (2008) with slight modification. Purple and orange SPP biscuits were prepared separately. Dough biscuits were prepared according to three concentrations of SPP powder $(2 \%$, $5 \%$, and $10 \%$ ), like the following, $137.2 \mathrm{~g}$ of flour and $2.8 \mathrm{~g}$ of SPP, $133.0 \mathrm{~g}$ of flour and $7 \mathrm{~g}$ of SPP, and $126 \mathrm{~g}$ of flour and $14 \mathrm{~g}$ of SPP. The biscuits dough was sheeted to a thickness of $1 \mathrm{~cm}$ with a rolling pin. The biscuits were shaped in a circle with a $5 \mathrm{~cm}$ diameter and were placed on a tray lined with baking paper and baked at $150^{\circ} \mathrm{C}$ for 15 mins in an electric oven.

\subsection{Sample analysis}

\subsubsection{Proximate composition of orange and purple sweet potato peel biscuits}

Fat, protein, carbohydrate, ash, moisture and dietary fibre content were analysed according to the method described by Analysis of Association of Official Analytical Chemistry (Association of Official Analytical Chemists, 2016). Total carbohydrate was calculated by difference (Dell and Reason, 1993).

\subsubsection{Sample extraction for antioxidant and phenolic content assays}

Methanolic extraction was performed according to Gull and his colleague (2018) with slight modifications. Briefly, each $2 \mathrm{~g}$ of samples were extracted with $10 \mathrm{~mL}$ of $80 \%$ methanol by using a magnetic stirrer located on the shaker for $2 \mathrm{hrs}$. Then, the mixture was filtered by a Newman filter paper. The filtered mixture was centrifuged at $3600 \mathrm{rpm}$ for $15 \mathrm{mins}\left(25^{\circ} \mathrm{C}\right)$ in a $30 \mathrm{~mL}$ plastic centrifuge tube. Then, the mixture was stored in a dried clean container for further analysis.

\subsubsection{Total phenolic content}

The extracted sample $(200 \mu \mathrm{L})$ was mixed with 3 $\mathrm{mL}$ of distilled water and $0.5 \mathrm{~mL}$ of Folin-Ciocalteu reagent and left for about 3 mins. Around $20 \mathrm{~g}$ of sodium carbonate was dissolved in $100 \mathrm{~mL}$ of distilled water to obtain a $20 \%$ sodium carbonate solution. A volume of 2 $\mathrm{mL}$ of $20 \%(\mathrm{w} / \mathrm{v})$ sodium carbonate was pipette into the same boiling tube before the sample was left for about 1 hr. All these steps were prepared in the dark. The sample was placed in the cuvette and the absorbance was measured at $650 \mathrm{~nm}$ by using UV-Vis Spectrophotometer (Model T60u, PG Instrument, USA). A standard solution of gallic acid was prepared by dissolving $0.1 \mathrm{~g}$ of gallic acid in $100 \mathrm{~mL}$ of distilled water. A serial dilution of $1.0,2.5,5.0$ and $7.5 \mathrm{~mL}$ was prepared. Next, $1 \mathrm{~mL}$ of each dilution was mixed with $4 \mathrm{~mL}$ of sodium carbonate and $5 \mathrm{~mL}$ of Folin-ciocalteu solution. The standard solution was left at $20^{\circ} \mathrm{C}$ for about 30 mins. Results were expressed as mg gallic acid per sample (Işik et al., 2011).

\subsubsection{Total flavonoid content}

Total flavonoid content was determined by using colorimetric aluminium chloride method with slight modification. Briefly, $1 \mathrm{~mL}$ of the extracted sample was pipetted and $4 \mathrm{~mL}$ of distilled water was added into a test tube. Sodium nitrite $(0.3 \mathrm{~mL})$ was added to the solution. After six mins, aluminium chloride hexahydrate $(0.3$ 
$\mathrm{mL}$ ) was added to the solution. $2 \mathrm{~mL}$ of sodium hydroxide $(1 \mathrm{M})$ was added. The mixture was vortex and immediately read at the absorbance of $510 \mathrm{~nm}$ against a blank reagent by using UV-vis spectrophotometer (Model T60u, PG Instrument, USA). Total flavonoid content was expressed as rutin equivalent in $\mu \mathrm{g} / 100 \mathrm{~g}$ of dry weight (Loizzo et al., 2012).

\subsubsection{Antioxidant activity}

\subsubsection{DPPH assay}

DPPH solution was prepared by dissolving $5.9 \mathrm{mg}$ of DPPH with $100 \mathrm{~mL}$ of methanol in a dark place. The extracted sample $(77 \mu \mathrm{L})$ was added into a test tube along with DPPH solution for 15 mins. After that, the samples were read by UV Vis Spectrophotometer (Model T60u, PG Instrument, USA) at $515 \mathrm{~nm}$ (Miliauskas et al., 2004).

$\%$ Inhibition $=[($ Absorption of blank-Absorption of sample)/Absorption of blank] $\times 100$

\subsubsection{ABTS assay}

Potassium persulfate $(2.45 \mathrm{mM})$ was added into the ABTS stock solution to produce ABTS+ radical and stored in the dark room for $15 \mathrm{hrs}$. ABTS+ radical was then diluted with deionized water to obtain an absorbance value of $0.7 \pm 0.2$ at $734 \mathrm{~nm}$. The sample extract $(200 \mu \mathrm{L})$ was added into $2 \mathrm{~mL}$ of ABTS free radical solution and allowed to stand for 30 mins. A standard curve was calibrated by using ascorbic acid of $10-50 \mu \mathrm{g} / \mathrm{mL}$. The absorbance of the standards and sample was measured at $734 \mathrm{~nm}$ by using UV-Vis Spectrophotometer (PG Instrument, Model T60u, USA). The test was conducted in triplicate and was calculated on average (Awika et al., 2003).

\subsubsection{Ferric reduction antioxidant potential assay}

The solution of FRAP was prepared by using $0.54 \mathrm{~g}$ of $\mathrm{FeCl}_{3}$ hexahydrate and was dissolved in $100 \mathrm{~mL}$ of deionised water. The buffer solution was prepared by dissolving $4 \mathrm{~mL}$ of glacial acetic acid and $0.78 \mathrm{~g}$ of sodium acetate in $250 \mathrm{~mL}$ of deionised water. TPTZ solution was prepared by mixing $0.34 \mathrm{~mL}$ of $\mathrm{HCl}$ in 100 $\mathrm{mL}$ of deionised water before adding $0.31 \mathrm{~g}$ of TPTZ powder. The extracted sample was diluted by dissolving $100 \mu \mathrm{L}$ of the extracted sample with $300 \mu \mathrm{L}$ of deionised water. Then, $100 \mu \mathrm{L}$ of the sample was pipetted into the test tube before the addition of $2.5 \mathrm{~mL}$ of $\mathrm{FeCl}_{3}, 2.5 \mathrm{~mL}$ of TPTZ and $25 \mathrm{~mL}$ of buffer solution into the same test tube. The sample was left for about 4 mins before the sample was read in the spectrometer (Model T60u, PG Instrument, USA) at $593 \mathrm{~nm}$. The test was done in triplicates and calculated on average (Kwon et al., 2013).

\subsubsection{Physicochemical test}

\subsubsection{Texture analysis}

The hardness and fracturability of biscuits were measured by the bend or snap or known as the threepoint break technique by using the Texture Analyser. The compression strength of biscuits was measured using the following conditions: Test mode: compression; pre-test speed: $1 \mathrm{~mm} / \mathrm{s}$; test speed: $3 \mathrm{~mm} / \mathrm{s}$; post-test speed: $10 \mathrm{~mm} / \mathrm{s}$; target mode: distance; distance: $4 \mathrm{~mm}$; trigger force: $50 \mathrm{~g}$; data acquisition rate: 500 PPS. Accessory: 3-Point Bending Rig (HDP/3PB) using $5 \mathrm{~kg}$ load cell, Heavy Duty Platform (HDP/90). The peak force $(\mathrm{g})$ and the mean distance at break $(\mathrm{mm})$ were recorded. The texture of biscuits was conducted by using Texture Analyser in triplicate.

\subsubsection{Colour}

The colour of biscuits was conducted by using Colour Spectrophotometer (Hunter Lab 4500L Model MiniScans E2, USA). The biscuits samples were placed into the petri dish and covered. The result $\mathrm{L}^{*}$ (luminosity), $\mathrm{A}^{*}$ (intensity of red colour) and $\mathrm{B}^{*}$ (intensity of yellow colour) was measured and calculated automatically. The test was done in triplicate.

\subsubsection{Sensory evaluation}

The characteristic sensory of the orange and purple sweet potato was evaluated using five different attributes by fifty untrained panellists from Universiti Tun Hussein Onn Malaysia. The panellists were from both sexes, and from different ages, they were requested to taste each sample separately without comparing it with another sample. The evaluated sensory attributes were crispiness, aroma, taste, colour, hardness, appearance and overall acceptability. The panellists rated the quality characteristics of each sample on a nine-point hedonic rating as described by (Stefanowicz, 2013). The panellists were asked to drink water to neutralize the taste between samples tasting.

\subsection{Statistical analysis}

The experiments were carried out in triplicate and the results were reported as mean $\pm \mathrm{SD}$ and subjected to statistical analysis using Statistical Package of the Social Sciences (SPSS) version 19 using one-way analysis of variance (ANOVA) by using SPSS. Duncan's Multiple Range Test was performed to determine the difference of mean, and $p<0.05$ was considered to be statistically significant.

\section{Results}

The proximate composition of sweet potato peel 
biscuits compared with control biscuits is presented in Table 1. The results showed that adding SPP powder has increased carbohydrate from 56.26 to $56.92 \%$, protein content from 5.7 to $6.1 \%$, ash from 0.046 to $0.072 \%$ and total dietary fibre from 0.8 to $2.3 \%$. Fat content was decreased from 34.8 to $34.2 \%$. The total dietary fibre was significantly different in OSPP $2 \%$ compared with PSPP $10 \%$.

The total phenolic and flavonoid content along with the antioxidant properties of sweet potato peel biscuits are presented in Table 2. The addition of OSPP increased the total phenolic from 101 to $111.24 \mu \mathrm{g} \mathrm{GAE} / \mathrm{mL}$, while PSPP increased the phenolic content from 126.26 to $141.02 \mu \mathrm{g} \mathrm{GAE} / \mathrm{mL}$. At $10 \%$ substitution of PSPP, the total phenolic content shows the highest value compared to OSPP $10 \%$. Similarly, an increase in the substitution of OSPP and PSPP increased the total flavonoid content. The biscuits with $10 \%$ of PSPP had the highest total flavonoid content $(42.9 \mu \mathrm{g} \mathrm{RU} / \mathrm{mL})$. However, OSPP at $5 \%$ and $10 \%$ concentration had similar value of total flavonoid content.

The antioxidant activities of SPP biscuits increased as the concentration of purple or orange sweet potato peel increased. The DPPH radical scavenging activity of $10 \%$ PSPP biscuit has the highest value (61.9\%) followed by $10 \%$ OSPP biscuit (52.9\%). The DPPH value was significantly $(\mathrm{P}<0.05)$ different between $5 \%$ PSPP biscuits and 5\% OSPP biscuits. FRAP values ranged from 40.8 to 177.8 (mM ferric reduced/g) for control and SPP biscuits, respectively. FRAP values demonstrated significant differences $(\mathrm{P}<0.05)$ in all PSPP and OSPP biscuits. OSPP biscuits showed similar FRAP values at all concentrations ranging from 123 to $125.05(\mathrm{mM}$ ferric reduced/g), but PSPP biscuits had higher FRAP values than OSPP at all three concentrations. Similarly, the ABTS values showed a significant difference $(\mathrm{P}<0.05)$ between control biscuits and SPP biscuits. The highest ABTS value was found at $10 \%$ PSPP biscuits $(42.83 \mu \mathrm{g}$ ascorbic $/ \mathrm{mL})$. The ABTS value of $10 \%$ OSPP biscuits $(24.39 \mu \mathrm{g}$ ascorbic/mL) was significantly similar to $5 \%$ PSPP biscuits $(22.38 \mu \mathrm{g}$
ascorbic/mL). Notably, the DPPH, FRAP and ABTS values for SPP biscuits followed a similar order of the total phenolic and total flavonoid contents.

Comparisons of the mean liking scores for the sensory attributes of the biscuits are presented in Table 3 . The appearance value of all the biscuits was relatively similar, ranging from 6.4 to 7.12 . The highest values of appearance were observed in PSPP $2 \%$ followed by OSPP $2 \%$. The colour of $2 \%$ OSPP and $2 \%$ PSPP biscuits were more significantly acceptable $(\mathrm{P}<0.05)$ than the other biscuits. Compared with the other biscuits, $2 \%$ PSPP had the highest value for taste and aroma. The crispiness values were significantly similar in the control biscuit (7.06), 2\% OSPP (7.12), and 2\% PSPP (7.12). At concentration of $2 \%$ of orange and purple sweet potato peel biscuits had the highest overall acceptability for sensory attributes.

The biscuits were measured by using texture analyser. The hardness values of SPP biscuits were lower than the control biscuits as shown in Table 4. The control biscuit has the longest distance which is $41.336 \mathrm{~mm}$. Notably, as SPP powder concentrations increased, the brittleness of the biscuits raised up. Moreover, PSPP $10 \%$ biscuit has the shortest distance $(37.847 \mathrm{~mm})$ followed by OSPP 10\% biscuit (39.829 mm).

The control biscuit had the highest brightness with $64.91 \pm 0.29$ for $L^{*}, a^{*}$ is $9.40 \pm 0.24$ and $b^{*} 39.23 \pm 0.45$. The value of $\mathrm{L}^{*}$ for OSPP and PSPP biscuits decreased as the concentrations of peels increased as shown in Table 5. No specific trend is observed in the change in $a^{*}$ value upon the addition of orange or purple sweet potato peel. As indicated by the $b^{*}$ value, the yellowness of orange sweet potato peel biscuits was significantly higher than purple sweet potato peel biscuits.

\section{Discussion}

The moisture content of sweet potato peel biscuits was below 5\% which support the shelf life against the microbial attack of any form of spoilage as mentioned by Calligaris et al. (2007) who suggested that less than $10 \%$

Table 1. The proximate composition of orange and purple sweet potato peel biscuits comparing with control biscuits (g/100 $\mathrm{g}$ dry matter)

\begin{tabular}{cccccccc}
\hline Nutritional content (\%) & CB & OSPP2\% & PSPP2\% & OSPP5\% & PSPP5\% & OSPP10\% & PSPP10\% \\
\hline Carbohydrates & $56.21^{\mathrm{d}}$ & $56^{\mathrm{d}}$ & $56.26^{\mathrm{d}}$ & $56.52^{\mathrm{c}}$ & $56.75^{\mathrm{b}}$ & $56.88^{\mathrm{b}}$ & $56.92^{\mathrm{a}}$ \\
Proteins & $5.2^{\mathrm{c}}$ & $5.7^{\mathrm{b}}$ & $5.7^{\mathrm{b}}$ & $6.1^{\mathrm{a}}$ & $5.9^{\mathrm{b}}$ & $6.3^{\mathrm{a}}$ & $6.1^{\mathrm{a}}$ \\
Fats & $34.8^{\mathrm{a}}$ & $34.3^{\mathrm{c}}$ & $34.2^{\mathrm{c}}$ & $34.3^{\mathrm{c}}$ & $34.4^{\mathrm{b}}$ & $34.3^{\mathrm{b}}$ & $34.2^{\mathrm{b}}$ \\
Ash & $0.046^{\mathrm{e}}$ & $0.06^{\mathrm{d}}$ & $0.064^{\mathrm{c}}$ & $0.067^{\mathrm{b}}$ & $0.068^{\mathrm{b}}$ & $0.07^{\mathrm{a}}$ & $0.072^{\mathrm{a}}$ \\
Moisture content & $3.74^{\mathrm{d}}$ & $3.82^{\mathrm{c}}$ & $3.81^{\mathrm{c}}$ & $3.86^{\mathrm{b}}$ & $3.84^{\mathrm{b}}$ & $3.88^{\mathrm{a}}$ & $3.89^{\mathrm{a}}$ \\
Total dietary fiber & $0.8^{\mathrm{d}}$ & $2^{\mathrm{b}}$ & $1.7^{\mathrm{c}}$ & $2.2^{\mathrm{b}}$ & $1.9^{\mathrm{b}}$ & $2.5^{\mathrm{a}}$ & $2.3^{\mathrm{a}}$ \\
\hline
\end{tabular}

CB: Control biscuits, OSPP: Orange sweet potato peel, PSPP: Purple sweet potato peel. Values are presented as mean \pm SD, $\mathrm{n}=$ 3 . Values with the same superscript within the same column are not significantly different $(\mathrm{P}>0.05)$. 
Table 2. Total phenolic and flavonoid content, and antioxidant properties of sweet potato peel biscuits.

\begin{tabular}{|c|c|c|c|c|c|}
\hline Samples & $\begin{array}{c}\text { TPC } \\
(\mu \mathrm{g} \mathrm{GAE} / \mathrm{mL})\end{array}$ & $\begin{array}{c}\text { TFC } \\
(\mu \mathrm{g} \mathrm{RU} / \mathrm{mL})\end{array}$ & \%Inhibition DPPH & $\begin{array}{c}\text { FRAP } \\
\text { (mM ferric reduced } / \mathrm{g})\end{array}$ & $\begin{array}{c}\text { ABTS } \\
(\mu \mathrm{g} \text { ascorbic } / \mathrm{mL})\end{array}$ \\
\hline $\mathrm{CB}$ & $75.25 \pm 0.40^{\mathrm{e}}$ & $8.16 \pm 0.30^{d}$ & $5.9 \pm 0.125^{\mathrm{d}}$ & $40.82 \pm 0.06^{\mathrm{c}}$ & $0.57 \pm 0.009^{\mathrm{e}}$ \\
\hline OSPP $2 \%$ & $101.67 \pm 1.67^{\mathrm{d}}$ & $22.27 \pm 1.65^{\mathrm{b}}$ & $25 \pm 0.306^{\mathrm{d}}$ & $123.08 \pm 2.60^{\mathrm{d}}$ & $2.75 \pm 0.008^{d}$ \\
\hline OSPP $5 \%$ & $102.87 \pm 0.22^{\mathrm{d}}$ & $30.41 \pm 0.05^{\mathrm{a}}$ & $48 \pm 0.165^{b}$ & $125 \pm 0.09^{\mathrm{d}}$ & $19.50 \pm 0.001^{\mathrm{b}}$ \\
\hline OSPP $10 \%$ & $111.24 \pm 0.27^{\mathrm{d}}$ & $30.66 \pm 0.05^{\mathrm{a}}$ & $52.9 \pm 0.139^{b}$ & $125.04 \pm 0.09^{d}$ & $24.39 \pm 0.002^{\mathrm{b}}$ \\
\hline PSPP2\% & $126.26 \pm 2.14^{\mathrm{c}}$ & $13.31 \pm 7.03^{\mathrm{c}}$ & $39 \pm 0.280^{\mathrm{c}}$ & $139.09 \pm 1.23^{\mathrm{c}}$ & $8.57 \pm 0.006^{\mathrm{c}}$ \\
\hline PSPP $5 \%$ & $134.64 \pm 10.38^{b}$ & $21.38 \pm 0.05^{\mathrm{b}}$ & $43.04 \pm 0.195^{\mathrm{c}}$ & $165.84 \pm 1.98^{b}$ & $22.38 \pm 0.004^{\mathrm{b}}$ \\
\hline PSPP $10 \%$ & $141.02 \pm 2.96^{\mathrm{a}}$ & $42.9 \pm 0.09^{\mathrm{a}}$ & $61.9 \pm 0.090^{\mathrm{a}}$ & $177.73 \pm 0.16^{\mathrm{a}}$ & $42.83 \pm 0.001^{\mathrm{a}}$ \\
\hline
\end{tabular}

CB: Control biscuits, OSPP: Orange sweet potato peel, PSPP: Purple sweet potato peel. Values are presented as mean \pm SD, $\mathrm{n}=$ 3. Values with the same superscript within the same column are not significantly different $(\mathrm{P}>0.05)$.

Table 3. The mean and standard deviation of sensory evaluation for 7 samples of biscuits.

\begin{tabular}{lccccccc}
\hline \multicolumn{1}{c}{ Attributes } & CB & OSPP 2\% & OSPP 5\% & OSPP 10\% & PSPP 2\% & PSPP 5\% & PSPP 10\% \\
\hline Appearance & $6.9 \pm 1.3^{\mathrm{a}}$ & $6.96 \pm 1.3^{\mathrm{a}}$ & $6.4 \pm 1.44^{\mathrm{b}}$ & $6.66 \pm 1.6^{\mathrm{b}}$ & $7.12 \pm 1.2^{\mathrm{a}}$ & $6.7 \pm 1.2^{\mathrm{b}}$ & $6.58 \pm 1.5^{\mathrm{b}}$ \\
Colour & $6.86 \pm 1.4^{\mathrm{a}}$ & $6.98 \pm 1.5^{\mathrm{a}}$ & $6.32 \pm 1^{\mathrm{b}}$ & $5.98 \pm 1.6^{\mathrm{c}}$ & $6.94 \pm 1.2^{\mathrm{a}}$ & $6.52 \pm 1.1^{\mathrm{b}}$ & $6.4 \pm 1.3^{\mathrm{b}}$ \\
Taste & $6.84 \pm 1.6^{\mathrm{c}}$ & $7.12 \pm 1.5^{\mathrm{b}}$ & $5.96 \pm 1.7^{\mathrm{e}}$ & $6.16 \pm 1.8^{\mathrm{e}}$ & $7.36 \pm 1.3^{\mathrm{a}}$ & $6.62 \pm 1.1^{\mathrm{d}}$ & $6.18 \pm 1.3^{\mathrm{e}}$ \\
Aroma & $6.96 \pm 1.5^{\mathrm{a}}$ & $6.9 \pm 1.5^{\mathrm{b}}$ & $6.28 \pm 1.4^{\mathrm{d}}$ & $6.54 \pm 1.5^{\mathrm{c}}$ & $6.94 \pm 1.3^{\mathrm{a}}$ & $6.54 \pm 1.2^{\mathrm{c}}$ & $6.32 \pm 1.3^{\mathrm{d}}$ \\
Hardness & $6.96 \pm 1.7^{\mathrm{b}}$ & $7.1 \pm 1.5^{\mathrm{a}}$ & $5.28 \pm 1.8^{\mathrm{d}}$ & $6.04 \pm 1.5^{\mathrm{c}}$ & $7.26 \pm 1.1^{\mathrm{a}}$ & $6.24 \pm 1.1^{\mathrm{c}}$ & $5.66 \pm 1.3^{\mathrm{d}}$ \\
Crispiness & $7.06 \pm 1.6^{\mathrm{a}}$ & $7.12 \pm 1.3^{\mathrm{a}}$ & $5.3 \pm 1.8^{\mathrm{c}}$ & $6.0 \pm 1.6^{\mathrm{b}}$ & $7.12 \pm 1^{\mathrm{a}}$ & $6.06 \pm 1.2^{\mathrm{b}}$ & $5.66 \pm 1.3^{\mathrm{c}}$ \\
Overall acceptability & $7.18 \pm 0.4^{\mathrm{b}}$ & $7.4 \pm 1.3^{\mathrm{a}}$ & $5.7 \pm 1.8^{\mathrm{e}}$ & $6.34 \pm 1.5^{\mathrm{c}}$ & $7.42 \pm 0.9^{\mathrm{a}}$ & $6.44 \pm 1.1^{\mathrm{c}}$ & $6.08 \pm 1.3^{\mathrm{d}}$ \\
\hline
\end{tabular}

CB: Control biscuits, OSPP: Orange sweet potato peel, PSPP: Purple sweet potato peel. Values are presented as mean \pm SD, $n=$ 3. Values with the same superscript within the same column are not significantly different $(\mathrm{P}>0.05)$.

Table 4. The hardness and fractur ability of sweet potato peel biscuits.

\begin{tabular}{lcc}
\hline \multirow{2}{*}{ Samples } & \multicolumn{2}{c}{ Force } \\
\cline { 2 - 3 } & Hardness (N) & Fracturability $(\mathrm{mm})$ \\
\hline CB & $1983.419^{\mathrm{a}}$ & $41.336^{\mathrm{a}}$ \\
OSPP 2\% & $1982.475^{\mathrm{a}}$ & $40.515^{\mathrm{a}}$ \\
OSPP 5\% & $1842.888^{\mathrm{b}}$ & $40.286^{\mathrm{a}}$ \\
OSPP 10\% & $1687.605^{\mathrm{c}}$ & $39.829^{\mathrm{b}}$ \\
PSPP 2\% & $1898.072^{\mathrm{b}}$ & $40.302^{\mathrm{a}}$ \\
PSPP 5\% & $1847.102^{\mathrm{b}}$ & $39.256^{\mathrm{b}}$ \\
PSPP 10\% & $1840.306^{\mathrm{b}}$ & $37.847^{\mathrm{c}}$ \\
\hline
\end{tabular}

CB: Control biscuits, OSPP: Orange sweet potato peel, PSPP: Purple sweet potato peel. Values are presented as mean \pm SD, $\mathrm{n}=3$. Values with the same superscript within the same column are not significantly different $(\mathrm{P}>0.05)$.

moisture content was suitable for storage stability. By increasing the sweet potato peel, the total dietary fibre was increased which was in agreement with the report of Ben Jeddou and his colleagues (2017) who indicated that incorporating potato peel powder with cake dough improved the dietary fibre content and reduce the total calorie. However, the protein content of sweet potato peel biscuit slightly increased which was similar in another report where potato peel powder was added to cake (Ben Jeddou et al., 2017).

Phenolic and flavonoid compounds are collectively considered a natural resource of antioxidants with a wide range of benefits for health (Brito et al., 2014; Rafiq et
Table 5. The mean and standard deviation of color for sweet potato peel biscuits.

\begin{tabular}{cccc}
\hline Samples & $\mathrm{L}^{*}$ & $\mathrm{a}^{*}$ & $\mathrm{~b}^{*}$ \\
\hline CB & $64.91 \pm 0.2^{\mathrm{a}}$ & $9.40 \pm 0.2^{\mathrm{b}}$ & $39.23 \pm 0.4^{\mathrm{a}}$ \\
OSPP 2\% & $65.49 \pm 0.7^{\mathrm{a}}$ & $8.14 \pm 0.1^{\mathrm{c}}$ & $38.59 \pm 0.6^{\mathrm{b}}$ \\
OSPP 5\% & $63.74 \pm 0.6^{\mathrm{a}}$ & $8.27 \pm 0^{\mathrm{c}}$ & $41.60 \pm 0.5^{\mathrm{a}}$ \\
OSPP 10\% & $51.56 \pm 1.1^{\mathrm{c}}$ & $12.59 \pm 0.3^{\mathrm{a}}$ & $41.98 \pm 0.9^{\mathrm{a}}$ \\
PSPP 2\% & $53.51 \pm 0.1^{\mathrm{b}}$ & $13.10 \pm 0.1^{\mathrm{a}}$ & $39.32 \pm 0^{\mathrm{a}}$ \\
PSPP 5\% & $55.33 \pm 1.4^{\mathrm{b}}$ & $10.00 \pm 0.3^{\mathrm{b}}$ & $35.37 \pm 0.2^{\mathrm{c}}$ \\
PSPP 10\% & $48.73 \pm 0.1^{\mathrm{c}}$ & $10.48 \pm 0.2^{\mathrm{b}}$ & $31.96 \pm 0.2^{\mathrm{d}}$ \\
\hline
\end{tabular}

CB: Control biscuits, OSPP: Orange sweet potato peel, PSPP: Purple sweet potato peel. Values are presented as mean $\pm \mathrm{SD}, \mathrm{n}$ $=3$. Values with the same superscript within the same column are not significantly different $(\mathrm{P}>0.05)$.

al., 2018). Previous studies reported the healthy benefits of incorporating citrus peel-rich polyphenols with bakery products (Rafiq et al., 2018). The current study presented an increment in the total phenolic and total flavonoid content of sweet potato peel biscuits. However, the highest concentration was in purple sweet potato peel biscuit due to the high concentration of anthocyanin and its derivatives (Musilová et al., 2017). Purple sweet potato flakes had increased the hepatic glutathione in rats fed with a high-cholesterol diet (Han et al., 2007). Therefore, incorporating peels fruits and/or vegetables such as pomegranate peel with producing functional foods improve the antioxidant properties of biscuits or bread dough. 
In the current study, purple and orange sweet potato peel had a DPPH free radical scavenging ability as shown in Table 2 which revealed that $10 \%$ of orange or purple sweet potato peel had the highest DPPH radical scavenging ability. The inhibitory activity of DPPH radicals for sweet potato peel biscuits was thought due to the high concentration of carotenoids and anthocyanins in orange and purple sweet potato respectively (Teow et al., 2007). Since the Millard reaction is responsible for the brown pigments melanoidins during the baking process, it has been reported previously that melanoidins possess antioxidant activities (Wang et al., 2011). Thus, Millard reaction could contribute to the antioxidant ability of orange and purple sweet potato peel biscuits produced.

The ability of orange and purple sweet potato peel biscuits in chelating $\mathrm{Fe}^{+2}$ is presented in Table 2. Orange or purple sweet potato peel biscuits were able to chelate $\mathrm{Fe}^{+2}$ in a dose-dependent manner. However, $10 \%$ purple sweet potato peel biscuits had the highest $\mathrm{Fe}^{+2}$ chelating ability. The presence of anthocyanin along with melanoidins may explain the antioxidant properties of purple sweet potato peel biscuits. It has been mentioned that soluble parts of Millard reaction compounds have metal chelating activity (Sharma and Gujral, 2014). ABTS assay was used to measure the radical scavenging activity by electron donation. In Table 2 , the results showed that the oxidation of ABTS has been inhibited by orange and purple sweet potato peel compared with control biscuits. These results were in agreement with Kim and his colleagues (2019) who reported that caffeic acid and vanillic acid quantity were correlated with the antioxidant properties of potato peels.

Food performance is associated mainly with sensory quality which can be measured relatively by grading the biscuits. Currently, there are plenty of sensory evaluation methods which are applied for various purposes in the food industry. As shown in Table 3, the incorporation of orange and purple sweet potato peel powder at $2 \%$ concentration improved the overall accessibility of the biscuits compared with control biscuits. Moreover, few studies reported that the higher concentrations of dry extracts would disturb the development of the gluten matrix in the dough due to the presents of higher amounts of total solids and decreasing amount of gluten protein in content (Shewry et al., 2002; Li et al., 2012). Therefore, the presence of peel would affect the texture of biscuits. The colour of biscuits is influenced by cooking or baking due to brown pigments that occur because of browning and caramelization reaction and also due to temperature and cooking time (RufiánHenares and Pastoriza, 2015). The orange sweet potato peel biscuit is slightly orange and red due to the presence of beta carotene in the peel (Teow et al., 2007). Purple sweet potato peel biscuit has purplish pigment due to the presence of anthocyanin (Liu et al., 2018). In addition, sweet potato peel has polyphenol oxidase and peroxidase activities along with polyphenols which are substrates for these enzymes. Thus, the brightness and yellowness of the biscuits could be decreased due to the enzymatic browning.

\section{Conclusion}

The chemical composition of sweet and purple sweet potato peel biscuits provides a good source of phytochemicals and dietary fibres. Biscuits enriched with PSPP showed a higher polyphenol content and therefore, PSPP incorporated biscuits had significant antioxidant activity. Thus, orange or purple sweet potato peel, a byproduct from the potato processing industry, could be utilized for the preparation of biscuits with improved functional and nutraceutical properties.

\section{Conflict of interest}

The authors herewith declare no conflict of interest.

\section{Acknowledgement}

Thank you to Universiti Tun Hussein Onn Malaysia for letting us conduct the experiments and research. We also would like to thank everyone who was involved directly and indirectly in this research. The authors would like to thank the Ministry of Higher Education of Malaysia (MOHE) for providing the grant under Fundamental Research Grant Scheme, FRGS Vot No. K 099 (FRGS/1/2018/WAB01/UTHM/02/1).

\section{References}

Ajila, C.M., Leelavathi, K. and Prasada Rao, U.J.S. (2008). Improvement of dietary fiber content and antioxidant properties in soft dough biscuits with the incorporation of mango peel powder. Journal of Cereal Science, 48(2), 319-326. https:// doi.org/10.1016/j.jcs.2007.10.001

Arslan, M., Rakha, A., Xiaobo, Z. and Mahmood, M.A. (2019). Complimenting gluten free bakery products with dietary fiber: Opportunities and constraints. Trends in Food Science and Technology, 83, 194202. https://doi.org/10.1016/j.tifs.2018.11.011

Association of Official Analytical Chemists. (2016). Appendix F: Guidelines for Standard Method Performance Requirements. AOAC Official Methods of Analysis. USA: AOAC.

Awika, J.M., Rooney, L.W., Wu, X., Prior, R.L. and Cisneros-Zevallos, L. (2003). Screening Methods to 
Measure Antioxidant Activity of Sorghum (Sorghum bicolor) and Sorghum Products. Journal of Agricultural and Food Chemistry, 51(23), 66576662. https://doi.org/10.1021/jf034790i

Bakar, M.F.A., Karim, F.A. and Perisamy, E. (2015). Comparison of phytochemicals and antioxidant properties of different fruit parts of selected artocarpus species from Sabah, Malaysia. Sains Malaysiana, 44(3), 355-363. https:// doi.org/10.17576/jsm-2015-4403-06

Ben Jeddou, K., Bouaziz, F., Zouari-Ellouzi, S., Chaari, F., Ellouz-Chaabouni, S., Ellouz-Ghorbel, R. and Nouri-Ellouz, O. (2017). Improvement of texture and sensory properties of cakes by addition of potato peel powder with high level of dietary fiber and protein. Food Chemistry, 217, 668-677. https:// doi.org/10.1016/j.foodchem.2016.08.081

Bhandari, M.R. and Kawabata, J. (2004). Organic acid, phenolic content and antioxidant activity of wild yam (Dioscorea spp.) tubers of Nepal. Food Chemistry, 88(2), 163-168. https://doi.org/10.1016/ j.foodchem.2003.12.027

Boobier, W.J., Baker, J.S. and Davies, B. (2006). Development of a healthy biscuit: An alternative approach to biscuit manufacture. Nutrition Journal, 5, 7. https://doi.org/10.1186/1475-2891-5-7

Brito, A., Ramirez, J.E., Areche, C., Sepúlveda, B. and Simirgiotis, M.J. (2014). HPLC-UV-MS profiles of phenolic compounds and antioxidant activity of fruits from three citrus species consumed in Northern Chile. Molecules, 19(11), 17400-17421. https:// doi.org/10.3390/molecules 191117400

Calligaris, S., Manzocco, L., Kravina, G. and Nicoli, M.C. (2007). Shelf-life modeling of bakery products by using oxidation indices. Journal of Agricultural and Food Chemistry, 55(5), 2004-2009. https:// doi.org/10.1021/jf063004h

Chandrasekara, A. and Joshepkumar, T. (2016). Roots and tuber crops as functional foods: A review on phytochemical constituents and their potential health benefits. International Journal of Food Science, 2016, $3631647 . \quad$ https:// doi.org/10.1155/2016/3631647

Cruz-Bravo, R.K., Guzmán-Maldonado, S.H., AraizaHerrera, H.A. and Zegbe, J.A. (2019). Storage alters physicochemical characteristics, bioactive compounds and antioxidant capacity of cactus pear fruit. Postharvest Biology and Technology, 150, 105111. j.postharvbio.2019.01.001

Dell, A. and Reason, A.J. (1993). Carbohydrate analysis. Current Opinion in Biotechnology, 4(1), 52-56.
https://doi.org/10.1016/0958-1669(93)90032-R

Gull, A., Prasad, K. and Kumar, P. (2018). Nutritional, antioxidant, microstructural and pasting properties of functional pasta. Journal of the Saudi Society of Agricultural Sciences, 17(2), 147-153. https:// doi.org/10.1016/j.jssas.2016.03.002

Han, K.H., Matsumoto, A., Shimada, K.I., Sekikawa, M. and Fukushima, M. (2007). Effects of anthocyaninrich purple potato flakes on antioxidant status in F344 rats fed a cholesterol-rich diet. British Journal of Nutrition, 98(5), 914-921. https://doi.org/10.1017/ S0007114507761792

Işik, E., Şahin, S., Demir, C. and Türkben, C. (2011). Determination of total phenolic content of raspberry and blackberry cultivars by immobilized horseradish peroxidase bioreactor. Journal of Food Composition and Analysis, 24(7), 944-949. https:// doi.org/10.1016/j.jfca.2011.01.016

Kalt, W. (2005). Effects of production and processing factors on major fruit and vegetable antioxidants. Journal of Food Science, 70(1), R11-R19. https:// doi.org/10.1111/j.1365-2621.2005.tb09053.x

Kim, J., Soh, S.Y., Bae, H. and Nam, S.Y. (2019). Antioxidant and phenolic contents in potatoes (Solanum tuberosum L.) and micropropagated potatoes. Applied Biological Chemistry, 62, 17. https://doi.org/10.1186/s13765-019-0422-8

Kwon, T.-H., Suh, H.-J., Lee, I.-K., Yun, B.-S., Kim, T.W., Hwang, D.-I. and Park, N.-H. (2013). Free radical scavenging activity of an aqueous extract of potato peel. European Food Research and Technology, 20(5),705-711. https://doi.org/10.1007/ s10811-007-9254-8

Lampe, J.W. (1999). Health effects of vegetables and fruit: Assessing mechanisms of action in human experimental studies. American Journal of Clinical Nutrition, 70(3), 475-490. https://doi.org/10.1093/ ajcn/70.3.475s

Lattimer, J.M. and Haub, M.D. (2010). Effects of dietary fiber and its components on metabolic health. Nutrients, 2(12), 1266-1289. https://doi.org/10.3390/ nu2121266

Lebesi, D.M. and Tzia, C. (2011). Effect of the Addition of Different Dietary Fiber and Edible Cereal Bran Sources on the Baking and Sensory Characteristics of Cupcakes. Food and Bioprocess Technology, 4(5), 710-722. https://doi.org/10.1007/s11947-009-0181-3

Li, P.H., Huang, C.C., Yang, M.Y. and Wang, C.C.R. (2012). Textural and sensory properties of salted noodles containing purple yam flour. Food Research International, 47(2), 223-228. https:// doi.org/10.1016/j.foodres.2011.06.035 
Liu, Y., Tikunov, Y., Schouten, R.E., Marcelis, L.F.M., Visser, R.G.F. and Bovy, A. (2018). Anthocyanin biosynthesis and degradation mechanisms in Solanaceous vegetables: A review. Frontiers in Chemistry, 6, 52. https://doi.org/10.3389/ fchem.2018.00052

Loizzo, M.R., Tundis, R., Bonesi, M., Menichini, F., Mastellone, V., Avallone, L. and Menichini, F. (2012). Radical scavenging, antioxidant and metal chelating activities of Annona cherimola Mill. (cherimoya) peel and pulp in relation to their total phenolic and total flavonoid contents. Journal of Food Composition and Analysis, 25(2), 179-184. https://doi.org/10.1016/j.jfca.2011.09.002

Mcrorie, J.W. and Fahey, G.C. (2013). A review of gastrointestinal physiology and the mechanisms underlying the health benefits of dietary fiber: Matching an effective fiber with specific patient needs. Clinical Nursing Studies, 1, 82-92. https:// doi.org/10.5430/cns.v1n4p82

Miliauskas, G., Venskutonis, P.R. and Van Beek, T.A. (2004). Screening of radical scavenging activity of some medicinal and aromatic plant extracts. Food Chemistry, 85(2), 231-237. https://doi.org/10.1016/ j.foodchem.2003.05.007

Musilová, J., Bystrick, J., Árvay, J. and Harangózo, L. (2017). Polyphenols and phenolic acids in sweet potato (Ipomoea batatas L.) roots, 12(6), 33-37. Potravinarstvo Slovak Journal of Food Sciences. https://doi.org/10.5219/705

Rafiq, S., Kaul, R., Sofi, S.A., Bashir, N., Nazir, F. and Ahmad Nayik, G. (2018). Citrus peel as a source of functional ingredient: A review. Journal of the Saudi Society of Agricultural Sciences, 17(4), 351-358. https://doi.org/10.1016/j.jssas.2016.07.006

Rufián-Henares, J.A. and Pastoriza, S. (2015). Browning: Non-enzymatic browning. Reference Module in Food Science. Encyclopedia of Food and Health, p. 515-521. Elsevier E-Book. https:// doi.org/10.1016/B978-0-12-384947-2.00089-1

Rumbaoa, R.G.O., Cornago, D.F. and Geronimo, I.M. (2009). Phenolic content and antioxidant capacity of Philippine sweet potato (Ipomoea batatas) varieties. Food Chemistry, 113(4), 1133-1138. https:// doi.org/10.1016/j.foodchem.2008.08.088

Serna-Cock, L., García-Gonzales, E. and Torres-León, C. (2016). Agro-industrial potential of the mango peel based on its nutritional and functional properties. Food Reviews International, 32(4), 364376. https:// doi.org/10.1080/87559129.2015.1094815

Sharma, P. and Gujral, H.S. (2014). Cookie making behavior of wheat-barley flour blends and effects on antioxidant properties. LWT - Food Science and Technology, 55(1), 301-307. https://doi.org/10.1016/ j.lwt.2013.08.019

Shewry, P.R., Halford, N.G., Belton, P.S. and Tatham, A.S. (2002). The structure and properties of gluten: An elastic protein from wheat grain. Philosophical Transactions of the Royal Society B: Biological Sciences, 357(1418), 133-142. https:// doi.org/10.1098/rstb.2001.1024

Stefanowicz, P. (2013). Sensory evaluation of food principles and practices. Journal of Wine Research, 24(1), 80-80. https:// doi.org/10.1080/09571264.2013.764662

Teow, C.C., Truong, V.D., McFeeters, R.F., Thompson, R.L., Pecota, K.V. and Yencho, G.C. (2007). Antioxidant activities, phenolic and $\beta$-carotene contents of sweet potato genotypes with varying flesh colours. Food Chemistry, 103(3), 829-838. https://doi.org/10.1016/j.foodchem.2006.09.033

Wang, H.Y., Qian, H. and Yao, W.R. (2011). Melanoidins produced by the Maillard reaction: Structure and biological activity. Food Chemistry, 128(3), 573-584. https://doi.org/10.1016/ j.foodchem.2011.03.075 